\title{
A PRODUÇÃO DO CONHECIMENTO SOBRE APRENDIZAGEM NA EDUCAÇÃO FÍSICA BRASILEIRA
}

\author{
Alison Pereira Batista, Instituto Fereal de Educação, ciência e Tecnologia do Rio \\ Grande do Norte - IFRN, Rio Grande do Norte - Brasil \\ José Pereira de Melo, Universidade Federal do Rio Grande do Norte-UFRN, Rio \\ Grande do Norte - Brasil \\ Allyson Carvalho de Araújo, Universidade Federal do Rio Grande do Norte - UFRN, \\ Rio Grande do Norte - Brasil \\ Maria Aparecida Dias, Universidade Federal do Rio Grande do Norte - UFRN, Rio \\ Grande do Norte - Brasil
}

\section{RESUMO}

O presente escrito traz reflexões gestadas durante a concepção de nosso estudo dissertativo e surgiu com o intuito de realizarmos algumas imersões exploratórias sobre o conhecimento produzido acerca da aprendizagem na Educação Física brasileira. Nesse sentido, tivemos como objetivo principal mapear e refletir sobre a produção do conhecimento em periódicos, programas de pós-graduação e anais de congressos, perseguindo a interface do corpo com a aprendizagem. $\mathrm{O}$ método de pesquisa utilizado foi o hermenêutico, através da análise de conteúdo (Bardin, 1977). Dentre as 825 publicações apreciadas, percebemos que apenas 687 expressavam alguma concepção teórica de aprendizagem em seu contexto e que apenas 242 das publicações evidenciaram a aprendizagem como objeto principal de seus estudos. A concepção de aprendizagem pautada no Comportamento Motor obteve 165 ocorrências, os trabalhos à luz das compreensões Psicopedagógicas somaram 158 trabalhos, as pesquisas articuladas com a perspectiva Histórico-Crítica foi a mais incidente com 252 arquivos, a Aprendizagem Significativa obteve 02 publicações, enquanto que a concepção Fenomenológica/Ciências Cognitivas esteve em 14 trabalhos. Acreditamos que a realização desse mapeamento sobre a temática da aprendizagem nos deu respaldo acadêmico para darmos continuidade aos nossos investimentos sobre aprendizagem na Educação Física escolar brasileira voltados para as perspectivas Fenomenológica/Ciências Cognitivas.

Palavras-Chave: Conhecimento; Aprendizagem; Educação Física.

\section{THE PRODUCTION OF KNOWLEDGE ABOUT THE LEARNING PROCESS ON PHYSICAL EDUCATION IN BRAZIL}

\footnotetext{
ABSTRACT

The following writing brings reflections that occurred during the conception of our dissertation. It came up in order to carry out some exploratory immersions on the knowledge that is produced about the learning on physical education in Brazil. Thus, 
our main objective is to chart and reflect on the production of knowledge from periodicals, post-graduation programs and congresses in order to pursue the body and learning interface. We used hermeneutics through the analysis of contents (Bardin, 1977). In a number of 825 publications, we perceived that only 687 expressed some theoretical conception of learning in their context and only 242 showed learning as the focus of study. The conception of learning based on Motor Behavior appeared 165 times; the works based on Psycho pedagogical comprehensions had 158 occurrences; the researches from a Historical-Critical perspective reached 252 files; the Meaningful Learning had only two publications whereas the Cognitive Science and Phenomenological was in 14 works. We believe this mapping about learning provides us with academic support so that we can carry on the investigation about learning on Physical Education in Brazilian schools based on the Cognitive Science and Phenomenological.

Key-Words: Knowledge. Learning. Physical Education.

\section{LA PRODUCCIÓN DE CONOCIMIENTOS SOBRE LA ENSEÑANZA DE EDUCACIÓN FÍSICA EN BRASIL}

\section{RESUMEN}

El texto aporta reflexiones hechas durante el diseño de nuestro estudio y se acercó con el fin de realizar algunas inmersiones exploratorias sobre el conocimiento producido sobre el aprendizaje de la Educación Física brasileña. En este sentido, tuvo como principal objetivo de trazar y reflexionar sobre la producción de conocimiento en revistas, programas de postgrado y actas de congresos, buscando temas relacionados con el cuerpo y el aprendizaje. El método de investigación utilizado fue el hermenéutico a través del análisis de contenido (Bardin, 1977). Entre las 825 publicaciones evaluadas, se dieron cuenta de que sólo 687 expresa una concepción teórica de aprendizaje en el contexto y que sólo 242 de las publicaciones mostraron el aprendizaje como el objeto principal de sus estudios. La concepción del aprendizaje pautado en Comportamiento Motor ha obtenido 165 de los casos, el trabajo a la luz de los entendimientos Psicopedagógica totalizó 158 textos, obras anclado en la perspectiva histórico-crítico fue el más frecuente con 252 archivos, el Aprendizaje Significativo recibió 02 publicaciones, mientras que el diseño fenomenológico / Ciencias Cognitivas estuvieron presentes en 14 estudios. Creemos que la realización de esta misión en el tema del aprendizaje ayuda a dar continuidad a nuestras inversiones en el aprendizaje de la Educación Física Brasileña centrado en las perspectivas de la fenomenológica / Ciencia Cognitiva.

Palabras-Clave: Conocimiento; Aprendizaje; Educación Física. 


\section{O CONTEXTO DA PESQUISA}

Nos últimos anos tem se produzido um conjunto significativo de pesquisas conhecidas por estado da arte ou estado do conhecimento. As pesquisas dessa natureza parecem trazer em comum o desafio de mapear e discutir certa produção acadêmica em diferentes campos do conhecimento, através de dissertações, teses, publicações em periódicos, anais, dentre outros. As pesquisas que se ocupam em realizar o estado da arte são reconhecidas por realizarem uma metodologia de caráter inventariante e descritiva da produção científica sobre o tema que se busca investigar, à luz de categorias e facetas que se caracterizam enquanto tais em cada trabalho e no conjunto deles, sob os quais o fenômeno passa a ser analisado. ${ }^{1}$

Além disso, as pesquisas sobre o estado do conhecimento passaram a ser compreendidas por parte dos pesquisadores como o ponto de partida para a realização de seus estudos, pois faz-se necessário conhecer os enfoques e abordagens científicas que foram concebidas ao longo do tempo sobre a temática investigada, como também suas nuances mais atuais. Nesse sentido, torna-se premente que pesquisadores realizem investimentos exploratórios sobre o estado do conhecimento antes de imergirem em um novo campo, objeto, metodologia ou foco de pesquisa.

Foi com o intuito de realizarmos uma dessas imersões exploratórias sobre o conhecimento produzido acerca da aprendizagem no âmbito da Educação Física brasileira que concebemos este escrito. Dessa forma, o trabalho em tela serviu como reflexão inicial para a construção de nossa dissertação de mestrado intitulada "Conhecimentos sobre o corpo: uma possibilidade de intervenção pedagógica nas aulas de Educação Física no ensino médio", defendida em 2013 no Programa de PósGraduação em Educação da Universidade Federal do Rio Grande do Norte. O referido trabalho dissertativo refletiu sobre a aprendizagem como um processo corporal, pois segundo Batista. $2: 15$

A aprendizagem ocorre no corpo inteiro e não somente numa área específica e restrita dele, por exemplo, no cérebro, como muitos acreditam. Na verdade, queremos deixar claro que compreendemos a aprendizagem como um processo não apenas de ordem cognitiva, mas principalmente de natureza corporal. 
Historicamente a temática da aprendizagem tem sido alvo de inúmeros estudos na Educação e na Educação Física, no entanto realizamos esta pesquisa com o objetivo principal de mapear e refletir sobre a produção do conhecimento em periódicos, programas de pós-graduação e anais de congressos, perseguindo a interface do corpo com a aprendizagem. Nesse sentido, para viabilizarmos o estudo pontuamos apenas os últimos cinco anos de produção do conhecimento (2007 a 2011), que marcaram o início da realização da dissertação. Tal recorte foi estabelecido como critério de mapeamento, pois esse período (cinco anos) é considerado pelos órgãos de fomento à pesquisa e avaliação do ensino superior como um período padrão para a verificação de desempenho.

O método de pesquisa que utilizamos foi o hermenêutico. A hermenêutica, como teoria da interpretação, considera os seguintes elementos: o texto e o contexto; a interpretação e a produção de significados; a compreensão e a criação de núcleos conceituais. ${ }^{3}$ Analisamos um total de 825 trabalhos. Através da análise de conteúdo, ${ }^{4}$ procedemos à organização do material ou pré-análise, realizada através da confecção das fichas de conteúdo. A codificação ou descrição analítica caracterizou-se pela identificação das temáticas recorrentes nas pesquisas e pela interpretação referencial iniciada desde a préanálise, sendo intensificada a partir da identificação dos núcleos de sentido.

A internet foi utilizada como ferramenta primordial para a realização do mapeamento, pois o acervo catalogado esteve disponibilizado integralmente na rede de informação. Para nortearmos a nossa pesquisa estabelecemos também algumas perguntas: Quantos trabalhos foram produzidos sobre aprendizagem nesse período? Qual arcabouço teórico sustentou a concepção de aprendizagem desses trabalhos? E quais estudos convergem com a nossa opção conceitual de aprendizagem?

Ao fazermos as primeiras leituras percebemos a necessidade de categorizarmos as concepções de aprendizagem disponíveis nos trabalhos, o que fizemos em cinco concepções: Comportamento Motor - foram os estudos relacionados à aprendizagem motora, desenvolvimento motor, biomecânica e pedagogia do esporte, concepção defendida por autores como Magill, Schmidt, Bernstein, Adams, Tani, Gallahue, Greco, 
Paes, entre outros; Psicopedagógica - concepção baseada nos estudos de autores como Piaget, Vygotisky, Wallon, Le Boulch, Freire, Bronfinbrenner, Krebs, Negrine, entre outros fundamentados na psicologia do desenvolvimento e áreas afins; Histórico-Crítica - defendida por autores como Paulo Freire, Perrenould, Hildebrandt, Coletivo de Autores, PCNs, Kunz, Bracht, Taffarel, Coll, Frenet, dentre outros que estabelecem a importância dos aspectos históricos e culturais no processo de aprendizagem; Aprendizagem Significativa - baseada nos estudos de David Ausubel; Fenomenológica/Ciências Cognitivas - baseada nas ideias de Merleau-Ponty, Maturana, Varela, Gonçalves, Nóbrega, Assmann, dentre outros autores que defendem a aprendizagem como processo corporal a partir de investimentos de diversas áreas do conhecimento como a filosofia, a biologia e as ciências cognitivas.

Nesse sentido, faremos um mapeamento da produção do conhecimento à partir das concepções de aprendizagem citadas acima, no entanto, iremos evidenciar os estudos fomentados a partir da concepção Fenomenológica/Ciências Cognitivas, pois a mesma coaduna com a opção conceitual de aprendizagem que tem fundamentado nossos trabalhos.

\section{A APRENDIZAGEM NA EDUCAÇÃO FÍSICA BRASILEIRA}

No âmbito da Educação Física brasileira, as primeiras concepções de aprendizagem tiveram sua origem no campo de investigação científica denominado de aprendizagem motora. De acordo com Darido; Rangel, ${ }^{5}$ esse campo teve seus primeiros estudos por volta de 1820. Porém, no âmbito da Educação Física, esse campo desenvolveu-se na década de 60, a partir da influência da ciência sobre a Educação Física.

Foi no início da década de 80 , com o retorno de brasileiros recém-doutores titulados no exterior, que os trabalhos a respeito da aprendizagem motora foram iniciados em nosso país. A aprendizagem motora, ao dar ênfase às pesquisas básicas, com o uso de metodologias reducionistas a partir do modelo da ciência moderna, contribuiu para o distanciamento da aplicação desses conhecimentos na prática profissional dos professores. 5 
Nessa perspectiva, a aprendizagem motora tem como objetivo principal a aquisição de habilidades motoras. Dessa forma, a aprendizagem é ocasionada, inicialmente, por meio de dois conceitos básicos primordiais: o estímulo-resposta.

Dentre as principais teorias concebidas a partir da aprendizagem motora, podemos destacar a teoria de processamento de informação, em que a aprendizagem é explicada de forma objetiva. O ser humano capta/recebe os estímulos por meio dos órgãos dos sentidos, esses estímulos são conduzidos pelas vias aferentes até o sistema nervoso central, após o seu processamento e decodificação no cérebro, são enviadas as devidas respostas pelas vias eferentes. No início dos estudos dessa área científica, essa foi a explicação mais aceita e, portanto, a mais utilizada para mostrar como o ser humano aprende. $^{6}$

Além da teoria do processamento de informação, outras teorias sobre aprendizagem, pautadas na aprendizagem motora, foram difundidas como as teorias do circuito aberto e do circuito fechado. Essas teorias caracterizaram-se pelo debate acerca do papel do feedback no controle dos movimentos. Enquanto na teoria de circuito fechado (periferalista), o feedback seria crucial durante a aprendizagem do movimento, na teoria de circuito aberto (centralista), o feedback não desempenha papel importante, uma vez que o movimento é controlado por um programa motor acionado em nível central. ${ }^{6}$

Compreendemos que essas teorias ligadas ao campo científico da aprendizagem motora, como também as várias outras existentes nessa linha teórica, tais como a Teoria do Esquema, têm a sua relevância principal associada aos estudos ligados ao desempenho e ao controle motor, observados nos esportes de rendimento e na recuperação de lesionados no sistema nervoso. Porém, na perspectiva educacional, essas teorias apresentam uma série de contradições, sendo a metáfora do homem-máquina a crítica mais veemente que fazemos. Nessa metáfora, há a equiparação do ser humano ao computador que possui um processador (cérebro) capaz de armazenar as informações captadas pelos órgãos dos sentidos e depois recuperá-las quando solicitadas. 
Embora, na atualidade, procedimentos metodológicos tradicionais que priorizam a aprendizagem motora ainda influenciem a prática pedagógica de professores de Educação Física, podemos perceber que esse campo científico vem sendo substituído na escola. Tal fato pode ser atribuído ao surgimento e à difusão das concepções históricocríticas de ensino, materializadas inicialmente pelos escritos "Educação Física: Ensino e Mudanças" (1991), "Metodologia do ensino da Educação Física" (1992), PCNs de Educação Física (1998).

Diante do contexto atual, consideramos que a Educação Física não tem mais o objetivo principal de proporcionar experiências de aprendizagem voltadas exclusivamente para a aquisição de habilidades motoras, pois essa concepção já foi ampliada. A aprendizagem dos gestos motores é importante e se faz necessária, no entanto, compreendemos que o objetivo principal da Educação Física seja dar aos alunos a oportunidade de acessar as diversas manifestações da cultura de movimento (jogos, lutas, danças, esportes, entre outras), por meio de aulas motivantes em que eles possam experienciar momentos práticos, expositivos e dialógicos, em espaços físicos variados, com participação ativa no processo de planejamento e execução das aulas. Além disso, faz-se necessário elencar discussões e temas atuais que façam parte da realidade dos educandos, no sentido de aproximá-los do seu entorno cultural.

Temos a consciência de que o corpo e o movimento são elementos indispensáveis para caracterização desse componente curricular e que as vivências corporais são de suma importância para a materialização de reflexões. No entanto, para que os alunos possam ter acesso a experiências mais significativas de aprendizagem, torna-se fundamental que saibam o porquê de estar fazendo este ou aquele movimento, que aprendam os contextos em que podem ser materializadas estas práticas corporais, os benefícios que elas trazem, como também que os professores, juntamente com seus alunos, construam experiências que propiciem o interpretar, o analisar e o ressignificar as manifestações dessa cultura de movimento.

Nesse sentido, compreendemos a aprendizagem significativa no âmbito da Educação Física como o acervo de aprendizagens que marcam significativamente os corpos dos

Conexões: revista da Faculdade de Educação Física da UNICAMP, Campinas, v. 13, n. 1, p. 79-98, jan./mar. 2015. ISSN: 1983-9030 
aprendizes. Ela é constituída por aprendizagens que ficam para vida e que são ressignificadas de acordo com os momentos em que precisamos nos valer delas. Além disso, esse tipo de aprendizagem atende aos interesses e necessidades do sujeito, servindo efetivamente para sua experiência vivida. Para que isso ocorra efetivamente, é fundamental que os conteúdos e as informações a serem incorporadas façam parte da realidade e do contexto dos aprendizes. Dessa forma, somente os sujeitos da aprendizagem poderão considerar se os ensinamentos apreendidos foram significativos ou não, por isso, ela tem um caráter subjetivo. No entanto, podemos inferir, por meio de instrumentos pedagógicos, elementos indicativos para a caracterização desse tipo de aprendizagem, como formular atividades envolventes e motivantes que possam ser úteis aos alunos em situações futuras de suas vidas; construir instrumentos avaliativos que possam relacionar o conhecimento vivenciado em sala de aula com o dia a dia e a realidade dos alunos; tornar o planejamento curricular mais dinâmico e participativo, envolvendo também os educandos nesse processo de sistematização do conhecimento.

Com o intuito de aprofundarmos as discussões em torno da produção do conhecimento sobre aprendizagem e suas aproximações com o corpo foi que concebemos as linhas a seguir. No entanto, para facilitarmos a compreensão dos leitores optamos por dividi-lo em três momentos distintos: periódicos, anais de congressos e programas de pósgraduação. Dessa forma, utilizamos de uma forma geral a estratégia de digitarmos a palavra "aprendizagem", nos sites pesquisados sem usar qualquer tipo de filtro (autor, título, resumo, texto indexado, texto completo) nas ferramentas de busca.

\section{PERIÓDICOS CIENTÍFICOS EM EDUCAÇÃO FÍSICA}

Fizeram parte do nosso mapeamento os periódicos da Revista Movimento, Revista do Colégio Brasileiro de Ciências do Esporte (RBCE), Revista Motriz, Revista Motrivivência, Revista de Educação Física da Universidade Estadual de Maringá e a Revista Pensar a Prática. Estabelecemos essa amostra intencional em virtude da influência e conceituação desses periódicos no universo científico da Educação Física e no grupo de estudos em que estamos inseridos. Segue abaixo o gráfico que apresenta as publicações de aprendizagem por periódicos. 


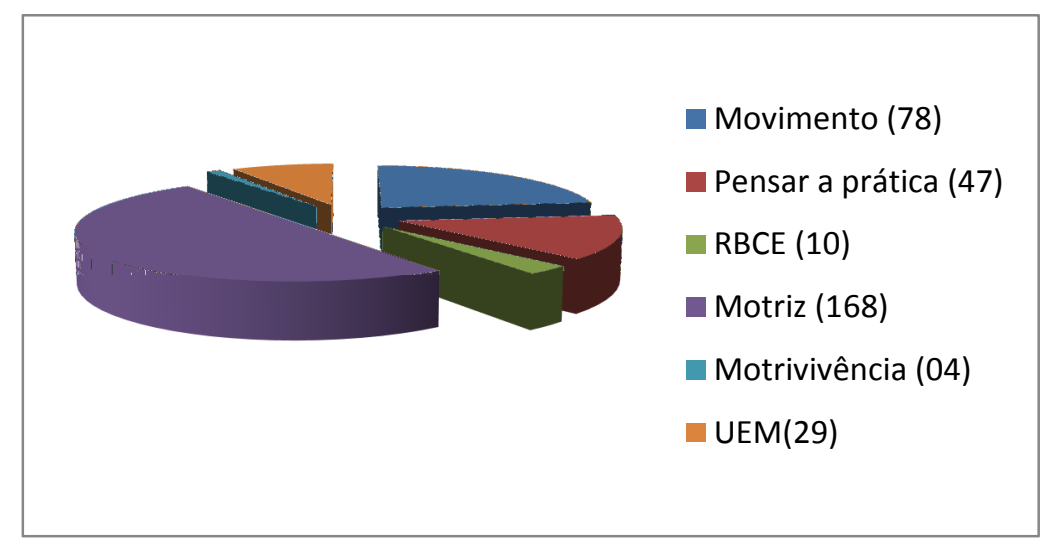

Figura 1: Publicações por periódicos.

Ressaltamos que dos 336 artigos apresentados pelas ferramentas de busca, 86 artigos foram descartados de nossa análise, pois alguns deles estavam indisponíveis para visualização, outros não trouxeram a palavra aprendizagem pelo menos uma vez em seu texto, enquanto outros trouxeram a palavra aprendizagem somente nas referências bibliográficas. Além disso, alguns usaram a palavra aprendizagem de uma forma geral, não evidenciando, nem nas entrelinhas, qual concepção teórica sustentava aquela expressão. Dessa forma, após o primeiro filtro de análise obtivemos uma redução para 250 publicações.

Buscando consolidar esse mapeamento sobre a produção do conhecimento nos periódicos investigados, apresentamos no gráfico abaixo as concepções de aprendizagem que fundamentaram tais publicações. 


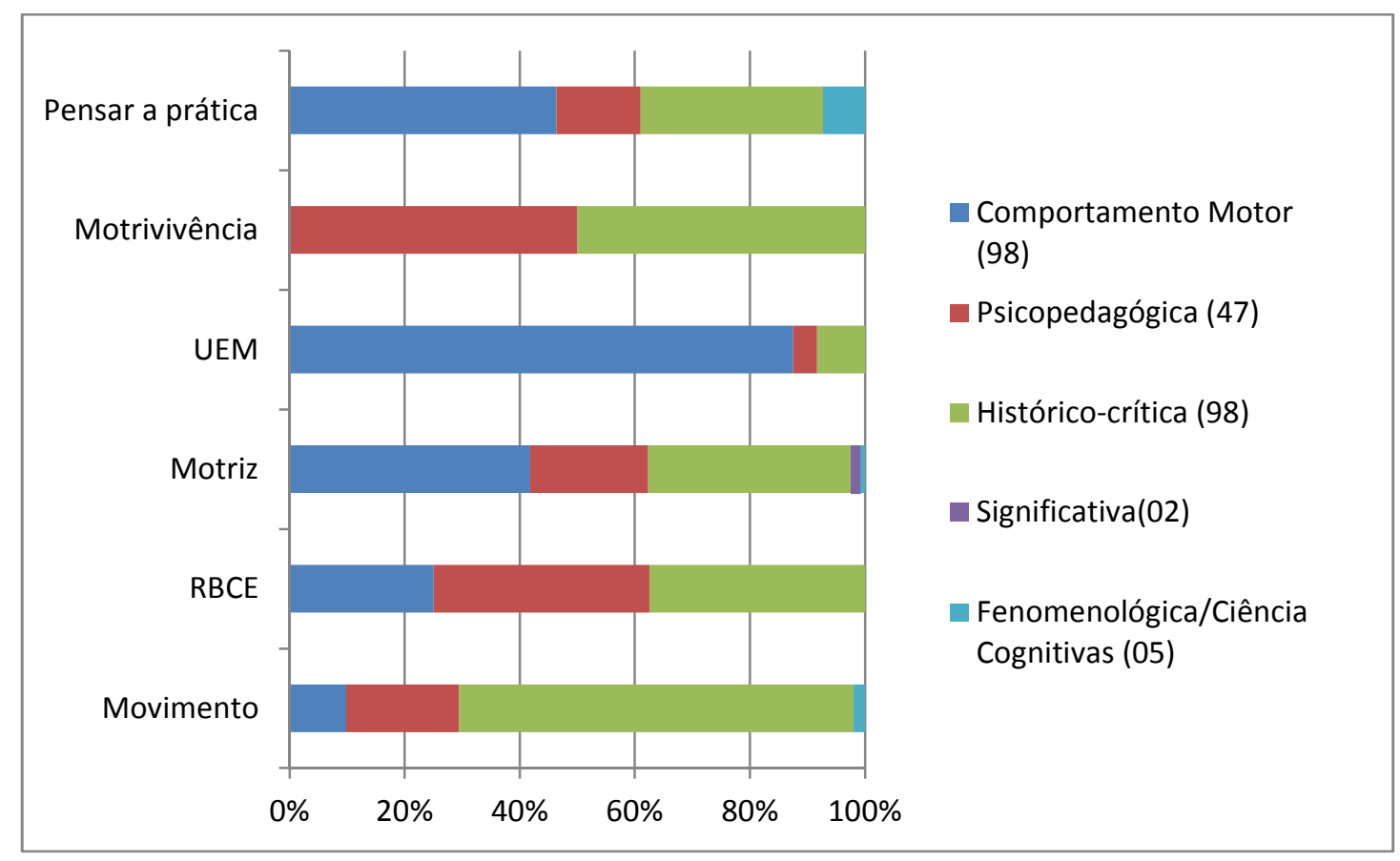

Figura 2: Concepção de aprendizagem por periódicos.

É possível observar que algumas concepções têm maior incidência de publicações do que outras, como por exemplo na Revista Movimento predomina a concepção históricocrítica, enquanto que na Revista da UEM predomina os estudos pautados pelo comportamento motor. Acreditamos que essa predominância de concepções em determinados periódicos está intimamente relacionada à existência de Grupos de Estudo e linhas de pesquisa de Pós-graduação em determinadas regiões do Brasil, como também ao próprio escopo da revista.

Considerando ainda o total de publicações, percebemos que apenas 3,2\% dos artigos trouxeram a concepção de aprendizagem a partir da Fenomenologia e das Ciências Cognitivas. Ao fazermos uma observação mais aprofundada sobre o termo aprendizagem selecionando desta vez as pesquisas pelo título do artigo e/ou palavraschave percebemos que apenas 15 artigos dentre os 250 trabalhos têm realmente a aprendizagem como temática principal.

Dentre os artigos observados à luz da Fenomenologia/Ciências Cognitivas destacamos na Revista Movimento o publicado em 2007 com o título "O aperfeiçoamento das técnicas de movimento em Dança", 7 embora o trabalho seja na área de dança ele faz Conexões: revista da Faculdade de Educação Física da UNICAMP, Campinas, v. 13, n. 1, p. 79-98, jan./mar. 2015. ISSN: 1983-9030 
uma breve discussão sobre aprendizagem a partir do corpo vivido de Merleau-Ponty. O autor afirma que a aprendizagem "fornece a ideia de corpo vivido, a qual vem sendo retomada pelas Ciências Cognitivas, como base para a compreensão da inscrição corporal do conhecimento nas teorias sobre aprendizagem."7:5

Outro artigo que coaduna com os nossos investimentos sobre aprendizagem é o da Revista Motriz, sob a autoria de Pereira; Mazzotti. ${ }^{8} \mathrm{O}$ trabalho identificou as representações sociais de Educação Física sustentadas pelos alunos trabalhadores do EJA. O foco principal deste trabalho não foi a aprendizagem, mas a construção do texto os autores reconhecem a importância do corpo para este processo, pois segundo Pereira; Mazzotti $^{8: 2}$ "a vivência da corporeidade em busca de uma aprendizagem mais humanizadora só seria possível pela percepção da pluralidade de corpos existentes no meio escolar e pela interlocução entre as práticas dos alunos e o fazer pedagógico".

A Revista Pensar a Prática também publicou em 2009 o artigo de Carlan; Domingues; Kunz. ${ }^{9}$ Este texto objetivou compreender o tratamento e o papel que a Didática vem assumindo nas práticas pedagógicas da Educação Física escolar, e se ela acompanhou as propostas metodológicas críticas. Os autores concluem que Educação Física escolar deve superar o reducionismo técnico-instrumental da Didática e redimensionar seu papel aproximando-se da dimensão pedagógica e epistemológica. No tocante à aprendizagem, os autores fundamentados na fenomenologia de Merleau-Ponty destacam por várias vezes a importância do "Se-movimentar humano", como também a existência de uma didática na Educação Física que considere que

\footnotetext{
$\mathrm{O}$ processo de ensino-aprendizagem não se restrinja à imitação de padrões de movimentos já fixados e busque a transcendência apreendida, que abre a possibilidade do encontro criativo ou inventivo com o mundo do movimento, o que altera a relação pedagógica dos professores com os estudantes, possibilitando um ambiente de criação pelo se movimentar. ${ }^{9: 7}$
}

As revistas investigadas apresentaram apenas cinco trabalhos que abordam a aprendizagem a partir de uma concepção ampliada de corpo. Foi possível identificar também que nenhuma dessas contribuições no âmbito da aprendizagem foram amplamente discutidas, e nem compõem os objetivos principais dos artigos. Nesse sentido, a nossa análise permitiu identificar e comprovar a reduzida produção em 
períodos da área de Educação Física que corroboraram com as discussões em torno da aprendizagem como um fenômeno corporal.

\section{ANAIS DE CONGRESSOS EM EDUCAÇÃO FÍSICA}

Fizemos a opção por três congressos científicos: Congresso Brasileiro de Ciências do Esporte - CONBRACE; Congresso Internacional de Educação Física e Motricidade Humana e Congresso Nacional de Educação Física, Saúde e Cultura Corporal. Esses eventos fizeram parte de nossa investigação por serem considerados pela comunidade acadêmica em que estamos inseridos, como espaços de excelência para discussão e construção do conhecimento em Educação Física, além de disponibilizarem os anais de seus congressos na internet.

O procedimento para a coleta de dados foi semelhante ao usado nos periódicos. Acessamos os sites oficiais dos congressos e digitamos a palavra aprendizagem nos anais. Vejamos os resultados vislumbrados no gráfico abaixo:

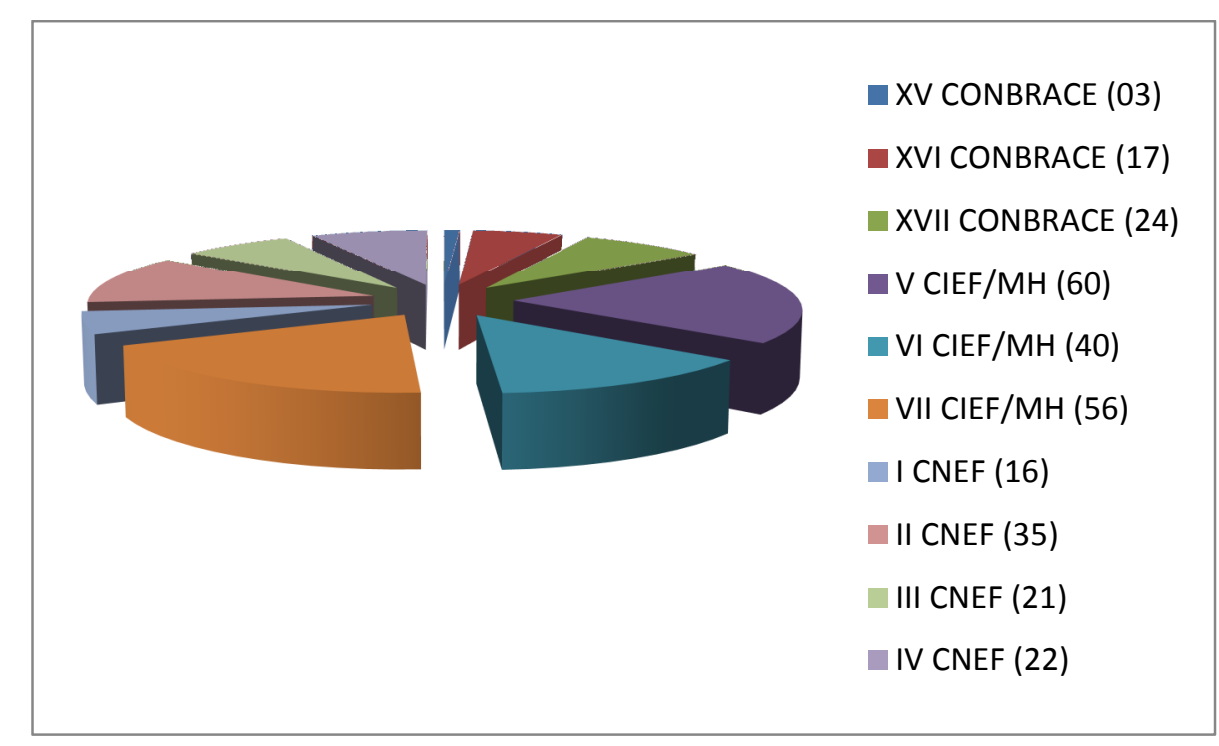

Figura 3: Publicações por anais.

Encontramos inicialmente 294 trabalhos, no entanto, vislumbramos que 52 deles não expunham uma concepção explícita de aprendizagem, reduzindo o montante para o número de 242. Observemos no gráfico abaixo as concepções de aprendizagem existentes nos anais dos congressos.

Conexões: revista da Faculdade de Educação Física da UNICAMP, Campinas, v. 13, n. 1, p. 79-98, jan./mar. 2015. ISSN: 1983-9030 


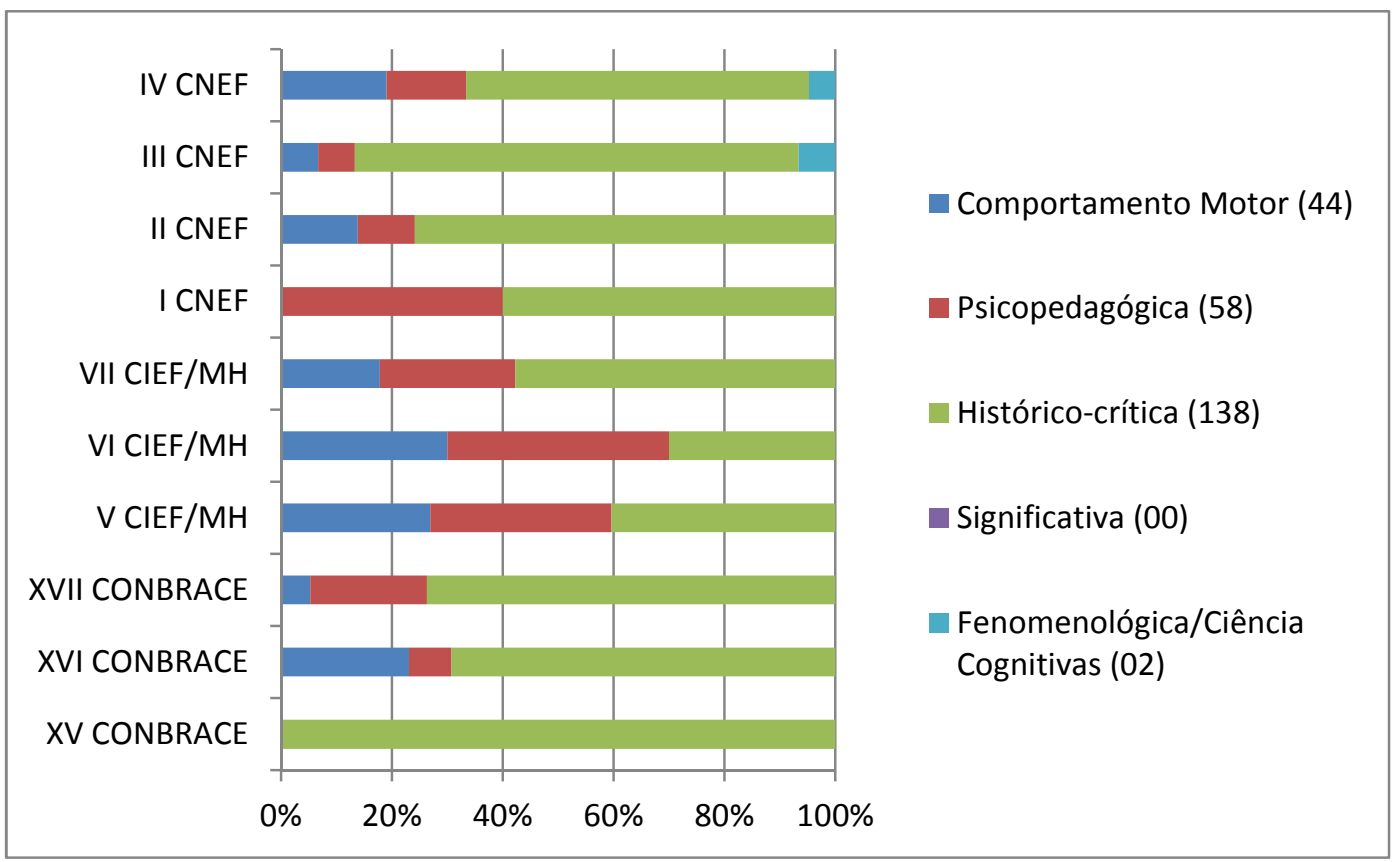

Figura 4: Concepção de aprendizagem por anais.

Ao analisarmos esses 242 trabalhos constatamos que apenas 32 traziam a palavra aprendizagem como foco principal, seja através do título ou das palavras-chave, enquanto que os demais trabalhos abordaram o tema durante o texto, mas não o aprofundaram, pois não tinham esse objetivo. É notório ainda a maior incidência de publicações pautadas pela concepção Histórico-Crítica, seguida pelas Psicopedagógica e Comportamento Motor. Consideramos que esse resultado acompanha uma tendência nacional da produção do conhecimento brasileiro, pois as matrizes teóricas que fundamentam tais concepções foram incorporadas pela Educação e a Educação Física a mais tempo do que os estudos produzidos, por exemplo, pela Fenomenologia/Ciências Cognitivas que obtiveram $0,67 \%$ do total de publicações. Além disso, temos observado uma ampla difusão das concepções críticas de ensino da Educação Física nas universidades, principalmente nos cursos de licenciatura em Educação Física provocando uma migração do foco das pesquisas voltadas historicamente da aprendizagem motora para a matriz histórico-crítica.

Dentre essa minoria de trabalhos observados destacamos o escrito por Cavalcanti; Porpino. ${ }^{10}$ As autoras discutiram sobre a ginástica rítmica a partir de um olhar estético. Ao posicionarem-se sobre o conhecer a partir Foucault afirmam que "talvez apenas 
conhecer não basta, é preciso apaixonar-se, desapaixonar-se, aprofundar-se nos sentidos, corporificar de uma vez por todas a aprendizagem, pois vivenciar é a chave". 10:373 Ao refletirem também sobre o adestramento motor na ginástica esclarecem que "acreditamos que a compreensão do movimento pela descoberta deve preceder a aprendizagem da forma, através de pequenos desafios, pois a exigência da forma a qualquer custo implica em adestramento, ocasionando uma aprendizagem limitada”. 10:374 Essas ideias defendidas pelas autoras estão em consonância como os nossos ideais sobre o trinômio corpo, aprendizagem e Educação Física.

\section{PROGRAMAS DE PÓS-GRADUAÇÃO EM EDUCAÇÃO E EDUCAÇÃO FÍSICA}

Ao acessarmos na época da realização do nosso estudo inventariante o portal da CAPES deparamos com 92 programas de pós-graduação em Educação e 37 programas de pósgraduação em Educação Física ativos no Brasil. Para realizarmos o mapeamento da produção do conhecimento sobre aprendizagem nesses programas foi necessário acrescentarmos alguns critérios para o viabilizarmos.

Em virtude da elevada quantidade de programas de pós-graduação, estabelecemos que fossem acessados somente os programas em Educação que tivessem conceito igual ou superior a cinco na avaliação trienal 2010 da CAPES, o que reduziu o montante para 21 programas, a saber: UFES, UFG, UFMG, UFU, UFPR, PUC-RIO, UERJ, UFF, UFRJ, UFRN, PUC-RS, UFPEL, UFRGS, UNISINOS, UFSCAR, UNESP/MAR, UNICAMP, UNIMEP, USP, PUC-SP e UFSCAR. Realizamos o mesmo procedimento para os programas de pós-graduação em Educação Física e excluímos os programas que embora estivessem enquadrados na área de avaliação Educação Física correspondiam a outras áreas do conhecimento como fisioterapia e fonoaudiologia, o que reduziu ao número de 20 programas das seguintes instituições: UNESP-RC, UCB, UNB, UFES, UFMG, UFV, FESP/UPE, UFPR, UEL, UNIVERSO, UFRJ, UGF, UFRGS, UFPEL, UDESC, UFSC, UNICAMP, UNIMEP, USJT e USP.

O procedimento para a coleta de dados na categoria programas de pós-graduação teve algumas particularidades com relação aos demais, pois foi necessário ser realizado por Conexões: revista da Faculdade de Educação Física da UNICAMP, Campinas, v. 13, n. 1, p. 79-98, jan./mar. 2015. ISSN: 1983-9030 
dois métodos distintos. Ao acessarmos os sites oficiais dos referidos programas constatamos duas situações: os que disponibilizavam a ferramenta de busca, semelhantemente às revistas eletrônicas e aos congressos científicos, como também, os programas que disponibilizavam apenas as listas de arquivos das Dissertações e Teses defendidas, sendo necessário o acesso individual por arquivo.

Em virtude do elevado número de programas de pós-graduação, como também, de publicações foi necessário adicionarmos um novo filtro a nossa investigação. Nesse sentido, realizamos o inventário contabilizando desde o início apenas as Dissertações e Teses que tivessem em seu título ou nas palavras-chave o termo aprendizagem, por isso, o total de publicações sobre aprendizagem no âmbito dos programas de pós-graduação obteve um número relativamente reduzido se comparado aos periódicos e anais.

Os programas de pós-graduação da área de Educação Física da UNESP/RC, UFPR, UNB, UFES, UFMG, UFV, FESP/UPE, UFPR, UNIVERSO, UFRJ, UGF, UNICAMP e UNIMEP e em Educação Matemática da UNESP/MAR não produziram durante o período analisado nenhuma dissertação ou tese sobre a temática da aprendizagem, enquanto que os programas da UFG (5), PUC-RIO (4), UNIMEP (4), UFU (3), UERJ (3), UNISINOS (3), UFSCAR (3), UFF (1), UFRGS/CIÊNCIAS DO MOVIMENTO HUMANO (1), UFPEL/ Educação Física (4), UDESC/Ciências do Movimento Humano (3), UFSC/Educação Física (3), USJT/Educação Física (1) produziram entre um e cinco publicações. Veremos no gráfico a seguir os programas de pós-graduação que produziram acima de 5 publicações. 


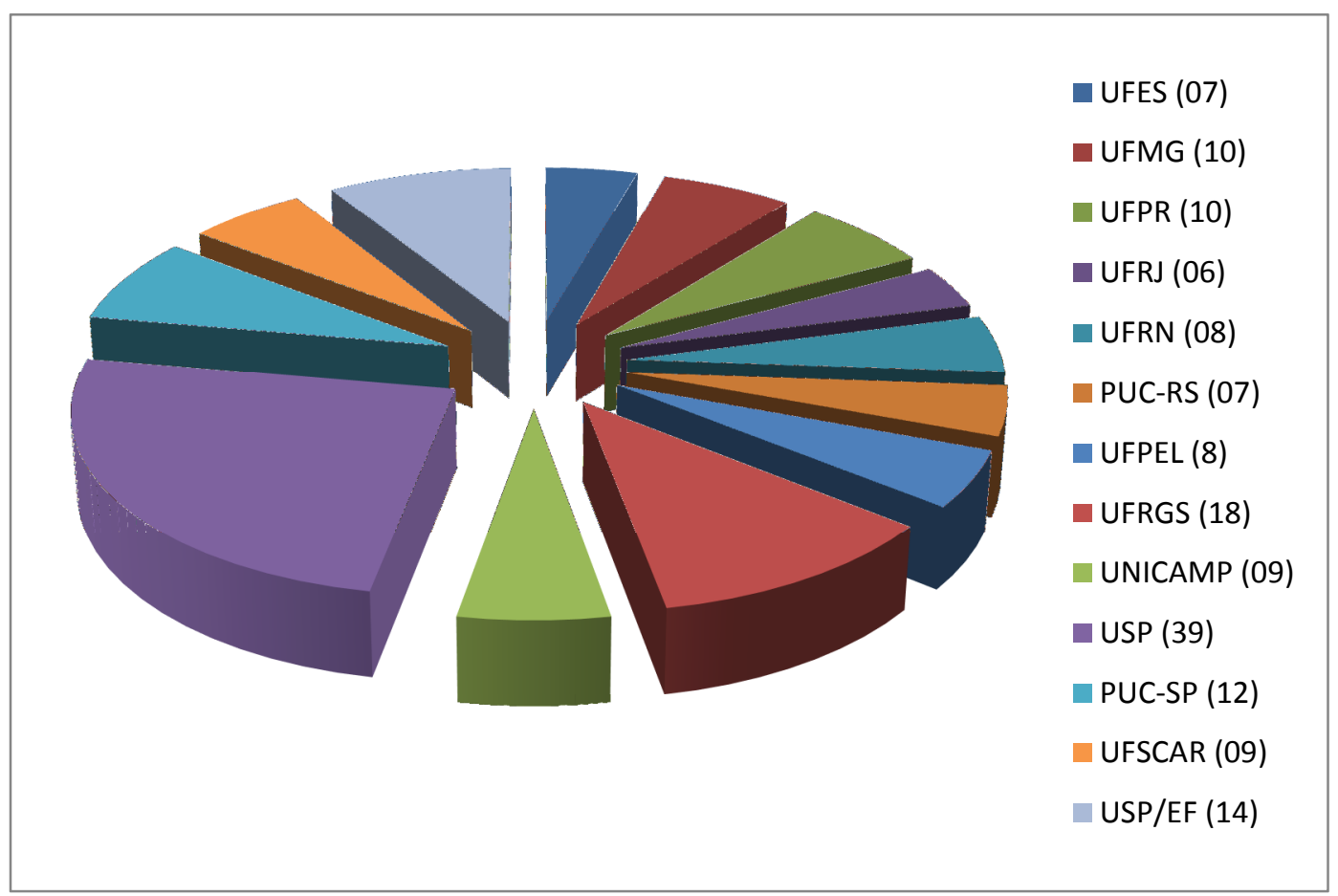

Figura 5: Publicações por programas de pós-graduação.

Os resultados acima também mostram que 60\% dos Programas de Pós-Graduação em Educação abordaram a temática da aprendizagem em suas produções acadêmicas, enquanto que $40 \%$ dessas produções foram realizadas nos Programas de Pós-Graduação em Educação Física. Isso mostra um certo equilíbrio na quantidade de publicações. No entanto, podemos compreender mais detalhadamente o teor dessas produções a partir do gráfico a seguir que mostra as concepções de aprendizagem por programas de pósgraduação. 


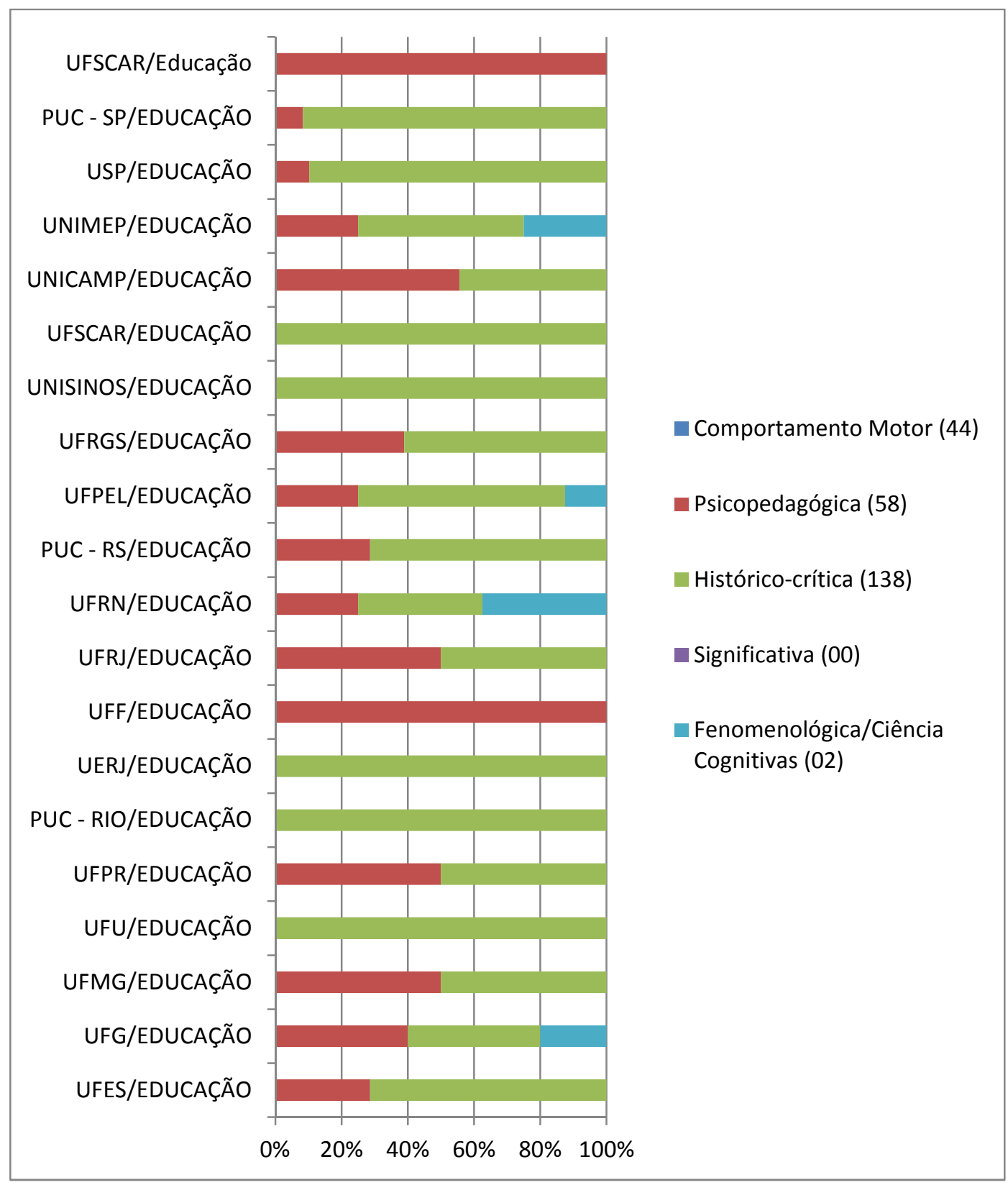

Figura 6: Concepção de aprendizagem por programa de pós-graduação.

Ao apreciarmos o gráfico acima percebemos mais uma vez a vertente histórico-crítica como a mais presente nas concepções de aprendizagem dos programas referindo-se a $57,4 \%$ da produção, enquanto que a concepção da aprendizagem pautada na fenomenologia, na filosofia e nas ciências cognitivas apresenta-se repetidamente como a minoria dos estudos com $3,6 \%$ do total.

Conexões: revista da Faculdade de Educação Física da UNICAMP, Campinas, v. 13, n. 1, p. 79-98, jan./mar. 2015. ISSN: 1983-9030 
Dentre essa minoria de trabalhos pautados na concepção Fenomenologia/Ciências Cognitivas destacamos a Tese defendida no programa de pós-graduação em educação da UFRN de Cordeiro. ${ }^{11}$ Tal publicação está em consonância com a matriz teórica que utilizamos em nossa dissertação, pois a pesquisadora fez uso de autores como Humberto Maturana, Francisco Varela, Hugo Assmann, Terezinha Petrúcia da Nóbrega, MerleauPonty entre outros que defendem a aprendizagem do corpo.

\section{CONSIDERAÇÕES FINAIS}

De acordo com os critérios estabelecidos no início deste escrito, no tocante à escolha dos locais investigados, ao método da pesquisa e à busca dos dados, pudemos contabilizar o número total de 825 publicações que continham o termo aprendizagem. Ao descartarmos as publicações que não estavam disponíveis para visualização, como também as que apareciam apenas nas referências ao termo aprendizagem, assim como, as que tratavam sobre aprendizagem de uma forma geral, mas não expressavam uma determinada concepção tivemos uma redução para número de 687 estudos. Avançando nesse processo investigativo e estabelecendo como critério que a palavra aprendizagem deveria estar contida pelo menos no título ou nas palavras-chave do trabalho, obtivemos uma redução para 242 publicações.

A concepção de aprendizagem pautada no comportamento motor obteve um total de 165 ocorrências, os trabalhos concebidos à luz das compreensões psicopedagógicas somaram 158 trabalhos, as pesquisas que articulam a aprendizagem com a perspectiva histórico-crítica tiveram a maior incidência, com 252 arquivos, a concepção da aprendizagem significativa obteve 02 publicações, enquanto que as pesquisas desenvolvidas sobre aprendizagem a partir do entendimento de que ela ocorre no corpo totalizaram o número de 14 trabalhos publicados.

Observando de forma ainda mais detalhada, pudemos perceber que embora esses 14 trabalhos coadunem com a concepção de corpo e aprendizagem que se afina com as escolhas teóricas e metodológicas dos autores desta pesquisa, os referidos trabalhos não discutiram sobre a aprendizagem dos conteúdos da Educação Física na escola. Tal 
constatação nos remete à necessidade de fomentarmos mais estudos na Educação Física sobre corpo e aprendizagem no âmbito educacional a partir da Fenomenologia/Ciências Cognitivas.

Acreditamos ainda que a realização desse mapeamento das produções científicas produzidas sobre a temática da aprendizagem nos deu um respaldo acadêmico mais relevante sobre a necessidade de produzirmos mais estudos na Educação Física escolar brasileira, voltados para as perspectivas Fenomenológica e das Ciências Cognitivas, que puderam ser vislumbradas como concepções ainda pouco investigadas na Educação e na Educação Física brasileira. Sendo assim, discutir sobre aprendizagem à luz dos estudos do corpo tornou-se um dos nossos desafios durante a elaboração de nossa dissertação, mas relacionar esse conhecimento teórico com a aprendizagem nas aulas de Educação Física na escola tornou-se a nossa contribuição mais efetiva em detrimento do número reduzido de trabalhos com esse olhar.

\section{REFERÊNCIAS}

${ }^{1}$ FERREIRA, N. S. A. As pesquisas denominadas "ESTADO DA ARTE". Revista Educação \& Sociedade, ano XXIII, n. 79, p. 257-272, ago. 2002.

${ }^{2}$ BATISTA, A. P.. Conhecimentos sobre o corpo: uma possibilidade de intervenção pedagógica nas aulas Educação Física no ensino médio, 2013. 287f. Dissertação (Mestrado em Educação) - Universidade Federal do Rio Grande do Norte, Natal, 2013.

${ }^{3}$ RICOEUR, P. Teoria da interpretação. Lisboa: Edições 70, 1978.

${ }^{4}$ BARDIN, L. Análise de conteúdo. Lisboa: Edições 70, 1977.

${ }^{5}$ DARIDO, S. C.; RANGEL, I. C. A. (Org.). Educação Física na escola: implicações para a prática pedagógica. Rio de janeiro: Guanabara Koogan, 2008. (Educação Física no Ensino Superior). 
${ }^{6}$ TANI, G. et al. Aprendizagem motora: tendências, perspectivas e aplicações. In: Revista Paulista de Educação Física, São Paulo, v. 18, p. 55-72, ago.2004.

${ }^{7}$ CASTRO, D. L. O aperfeiçoamento das técnicas de movimento em dança. Movimento, Porto Alegre, v. 13, n.1, p. 121-130, jan/abr. 2007.

${ }^{8}$ PEREIRA, G. M. S.; MAZZOTTI, T. B. Representações sociais de Educação Física por alunos trabalhadores do ensino noturno. Motriz, Rio Claro, v. 14, n.1, p. 53-62, jan/mar. 2008.

${ }^{9}$ CARLAN, P.; DOMINGUES, S. C.; KUNZ, E. Didática da Educação Física brasileira: uma compreensão da produção científica. Pensar a Prática, Goiania, v. 12, n. 3, p. 0111, set/dez. 2009.

${ }^{10}$ CAVAlCANTI, L. M. B.; PORPINO, K. O. O corpo belo transcende a regra: reflexões sobre beleza e educação na ginástica rítmica. In: Anais do Congresso Nacional de Educação Física, Saúde e Cultura, 4. , 2010, Recife.

${ }^{11}$ CORDEIRO, R. V. Corporeidade, dialogicidade e virtualidade: desvelando a aprendizagem. 2008. 226 f. Tese (Doutorado em Educação) - Universidade Federal do Rio Grande do Norte, Natal, 2008. 